NASA Technical Memorandum 100124

\title{
Regressed Relations for Forced Convection Heat Transfer in a Direct Injection Stratified Charge Rotary Engine
}

Chi M. Lee

Lewis Research Center

Cleveland, Ohio

and

Harold J. Schock

Michigan State University

East Lansing, Michigan

Prepared for the

1988 International Congress and Exposition

sponsored by the Society of Automotive Engineers, Inc.

Detroit, Michigan, February 29-March 4, 1988

\section{NRSA}

(NASA-TM-100124) EEGRESSED RELATIONS POA

N $88-13345$

FORCED CONVECTION HEAT TRANSFER IN A DIRECT

INJECTION STRATIFIED CHARGE ROTARY ENGINE

(NASA) $24 \mathrm{p}$ AVaII: NTIS HC AO3/MF AOI 


\title{
REGRESSED RELATIONS FOR FORCED CONVECTION HEAT TRANSFER
}

\section{IN A DIRECT INJECTION STRATIFIED CHARGE ROTARY ENGINE}

\author{
Chi M. Lee \\ National Aeronautics and Space Administration \\ Lewis Research Center \\ Cleveland, Ohio 44135
}

\author{
and \\ Harold J. Schock \\ Michigan State University \\ East Lansing, Michigan 48824
}

\begin{abstract}
SUMMARY
Currently, the heat transfer equation used in the rotary combustion engine (RCE) simulation model is taken from piston engine studies. These relations have been empirically developed by the experimental input coming from piston engines whose geometry differs considerably from that of the RCE. The objective of this work was to derive equations to estimate heat transfer coefficients in the combustion chamber of a RCE. This was accomplished by making detailed temperature and pressure measurements in a direct injection stratified charge (DISC) RCE under a range of conditions. For each specific measurement point, the local gas velocity was assumed equal to the local rotor tip speed. Local physical properties of the fluids were then calculated. Two types of correlation equations were derived and are described in this paper. The first correlation expresses the Nusselt number as a function of the Prandtl number, Reynolds number, and characteristic temperature ratio; the second correlation expresses the forced convection heat transfer coefficient as a function of fluid temperature, pressure, and velocity.
\end{abstract}

\section{INTRODUCTION}

The results of heat transfer studies over the past several decades (refs. 1 to 5) have been applied to internal combustion engine analysis to access engine performance and structural integrity. Within the past $5 \mathrm{yr}$, extensive implementation of this work in computer codes has been used to simulate piston engine operation. In general, the equations used for heat transfer analysis in the piston engine have taken the following form:

$$
\begin{gathered}
N u=0.021\left(\frac{T W}{T b}\right)^{-0.29}(P r)^{0.4}(R e)^{0.8} \\
N u=0.036(P r)^{0.33}(R e)^{0.8} \\
h=110\left[d^{0.2} p^{0.8}\left(6.18 C_{m}\right)^{0.8} T^{-0.53}\right]
\end{gathered}
$$


where equation ( 1 ) is used to estimate the heat transfer coefficient in the reactor (ref. 4); equation (2) is used to estimate the turbulent heat transfer coefficient through a flat plate (ref. 8); equation ( 3 ) is the equation derived by Woschni (ref. 5).

These equations have been found to be satisfactory when the constants in them were based on empirical information available for the piston engine of interest.

Previous simulations (refs. 7 to 9 ) of the heat transfer processes in the RCE have assumed that the turbulent gas-to-wall heat transfer coefficient is given by the McAdams correlation for turbulent flows in pipes; however, these assumptions were made without the benefit of the availability of detailed experimental data. Data to make this correlation possible was collected by NASA during this analysis.

The applicability of the above heat transfer equations to the rotary combustion engine is described in this study.

\section{ROTARY ENGINE TEST RIG}

The test rig (fig. 1) was constructed using a single rotor, rotary engine built by OMC, with a 39.6 in. 3 displacement. The engine is naturally aspirated and incorporates direct fuel injection combined with spark ignition to create a stratified charge environment for combustion.

One fuel injector and one spark plug were used in this configuration. The rotor was cooled by the intake air seeded with oil to eliminate the need for a main bearing lubrication system. End bearings were lubricated in a conventional fashion. Coolant is directed peripherally around the hot side of the rotor housing to simplify the rotor housing and the side housing geometry. Figure 2 shows the path of the coolant through the engine.

The fuel system consisted of a distributor type injection pump and a fourhole pencil injector which was located near the minor axis of the trochoid housing. The fuel used was an ASTM diesel check fuel with a cetane number of 53.7 .

A single spark plug located on the minor axis of the trochoid housing was used to initiate combustion. The single spark per power stroke was generated by a capacitive discharge ignition system.

Lubrication for the main bearings, rotor bearings, and the rotor seals was provided by two solenoid-operated metering pumps. The main bearing lubrication oil was a synthetic, two-cycle oil which was not recirculated but consumed in the combustion process. The heat of combustion of the oil was negligible in comparison to that of the fuel.

The remainder of the test rig consisted primarily of an eddy current dynamometer and an electric motor. The motor was capable of motoring the engine up to speeds of $3200 \mathrm{rpm}$, while the dynamometer could absorb engine torques up to $50 \mathrm{ft}-1 \mathrm{~b}_{f}$ at speeds up to $6000 \mathrm{rpm}$. 


\section{INSTRUMENTATION}

The flow of air into the engine was measured using a laminar flow element. The flow element was separated from the engine by a plenum chamber which dampened pulsations from the intake strokes of the engine. system.

Fuel flow was measured by a Flo-tron positive displacement flow metering

The engine coolant was a one-to-one solution by volume, of ethylene glycol and water. The coolant flow was measured by a turbine flowmeter. Both the inlet and outlet coolant temperatures were monitored along with the engine speed, exhaust temperature and housing temperatures to establish steady-state conditions.

The local average engine temperatures ( $\mathrm{fig}$. 3) were determined by the use of copper-constantan thermocouples mounted in the rotor housing. A total of 16 thermocouples were mounted in pairs in eight locations around the trochoid housing. At each location, one thermocouple was mounted directly behind the other in a straight line which was perpendicular to a tangent to the inner trochoid surface at that location ( $f$ ig. 4). The second thermocouple was placed $0.125 \mathrm{in}$. from the first thermocouple. The thermocouples were positioned in this manner so that average local heat flux (fig. 5) and average gas-side wall temperature calculations could be made. In addition, all of these thermocouple junctions were located in the midplane of the trochoid housing. Four additional thermocouples were mounted in pairs, in two locations in the coolant passage, to measure the coolant side surface temperature and the bulk coolant temperature.

Pressures in the combustion chamber of the engine were measured by a series of four water-cooled, piezoelectric pressure transducers. These transducers were mounted in the midplane of the trochoid housing in such a way that the chamber pressure would constantly be monitored (fig. 6). This constant pressure monitoring throughout all four engine cycles was made possible through the use of a NASA-developed electronic switching and correlating system called the Modular Engine Instrument System (MEIS). The composite pressure curve, which is a real-time measurement, was recorded on a digital waveform recorder. The waveform recorder incorporated a series of individual analog-to-digital (A-D) converters which permitted a number of individual signals to be recorded simultaneously. The commercially available waveform recorder (fig. 7) was modified such that it could be triggered by an external signal and then driven by an external clock. The recorder was triggered manually when a steady-state condition was reached with the engine. The recording was done in a crank angle reference frame as opposed to a time-base reference clock. The external clock signal and trigger were produced by a NASA designed MEIS/waveform recorder interface module.

Each A-D converter of the waveform recorder had $32 \mathrm{~K}$ bytes of memory associated with it, which translates into 32 complete, four-cycle, composite pressure curves. For each data point taken, 32 consecutive composite curves were recorded and automatically downloaded to a microcomputer having hard-disk memory capability. These 32 composite curves were ensemble-averaged in postrun time to form one average composite pressure curve representative of the engine conditions at the time data was taken. 
Exhaust emissions were measured by a Scott Research Laboratories Test Console. Sampling was taken at a remote module and pumped $30 \mathrm{ft}$ through a heated line to the emissions analyzers. The following equipment was used:

Scott Model 415 - Total HC Analyzer

Scott Model 250 - Paramagnetic $\mathrm{O}_{2}$

Detector

Scott Model 125 - NO/NOx Analyzer

Beckman Model 864 - $\mathrm{CO}_{2}$ Analyzer

Beckman Model 865 - CO Analyzer

\section{METHOD OF CALCULATION}

To simplify calculation, the following assumptions were made:

(1) Only convective heat transfer was considered.

(2) Assume no exhaust gas recirculation or inter-chamber gas leakage.

(3) Uniform chemical composition and gas temperature throughout the chamber at each instant of time.

(4) The gas and coolant physical properties can be computed from the average film temperature, local pressure, and composition.

(5) The local gas velocity is assumed to be the average surface tangential velocity (it is a time average and is not a spatial average) of the rotor.

The OMC test engine was run at four selected speeds: 2200, 2500, 2800, and $3200 \mathrm{rpm}$. Temperature and pressure data were taken at 16 thermocouples and four pressure transducers ( $f i g .4$ ) under steady-state operating conditions. The local gas composition was obtained by balancing equation (4). Knowing the temperature, pressure and gas composition, the local gas properties were calculated.

Gas side convective heat transfer calculations were based on a number of empirical and derived equations. Working fluid pressure, exhaust composition, and temperature measurements were collected from three different data acquisition systems. First, the pressure transducers and MEIS measure and correlate local gas pressures. For each crank angle, the pressure is assumed to be constant throughout the combustion chamber. Second, the Gould 9000 system provides the high speed digitization necessary to record the pressure data. In the intake and compression processes of the direct injection RCE, the working fluid is simply air and water vapor. During combustion, information is based on sampling emissions and calculations using the equation:

$$
\begin{aligned}
\mathrm{n}_{1} \mathrm{C}_{9} \mathrm{H}_{19}+\mathrm{n}_{2} \mathrm{O}_{2}+\mathrm{n}_{3} \mathrm{~N}_{2}+\mathrm{n}_{4} \mathrm{H}_{2} \mathrm{O} \rightarrow \mathrm{n}_{5} \mathrm{CO}_{2}+\mathrm{n}_{6} \mathrm{H}_{2} \mathrm{O}+\mathrm{n}_{7} \mathrm{~N}_{2}+\mathrm{n}_{8} \mathrm{O}_{2} \\
+\mathrm{n}_{9} \mathrm{CO}+\mathrm{n}_{10} \mathrm{NO}+\mathrm{n}_{11} \mathrm{C}_{9} \mathrm{H}_{19}
\end{aligned}
$$

The summation of $n_{5}$ through $n_{11}$ is the total moles/cycle $\left(\Sigma n_{j}\right)$ of the gas mixture during combustion and exhaust. Third, the values ng through nil 
are measured by the Scott Emission Analyzer and recorded in the Escort system. The local volume of the working chamber is calculated from equation (10):

$$
\bar{V}(\alpha)=\bar{V}_{\min }+\frac{3 \sqrt{3}}{2} \text { eRb }\left(1-\cos \frac{2}{3} \alpha\right)
$$

The local working fluid temperature can be calculated by the modified ideal gas law equation:

$$
P \bar{V}(\alpha)=Z\left(\sum n_{\mathfrak{j}}\right) R \operatorname{Tg}(\alpha)
$$

Using the area surrounding thermocouples 3 and 4 as an example (fig. 4), the local average heat loss can be calculated by the equation:

$$
\left(\frac{Q}{A}\right)_{3-4}=\frac{k_{1}}{S_{1}}\left(T_{3}-T_{4}\right)
$$

from the equation:

Local gas side average wall temperature can be extrapolated

$$
\left(\frac{Q}{A}\right)_{3-4}=\frac{k_{2}}{S_{2}}\left(T_{w g}-T_{3}\right)
$$

Finally, the local gas side heat transfer coefficient is calculated from the equation:

$$
\left(\frac{Q}{A}\right)_{3-4}=h_{g}(\alpha)\left(T_{g}(\alpha)-T_{w g}(\alpha)\right)
$$

\section{METHOD OF CORRELATION}

The transfer heat in gases has been widely studied (refs. 2 to 5 ). The results of this work have been correlated by a variety of methods which, in general, can be represented by two different kinds of correlation. The Correlation I is to correlate the Nusselt number as a function of the Reynolds number, Prandt 1 Number, and characteristic temperature ratio. Correlation II is to correlate the gas side transfer coefficient as a function of gas phase temperature, pressure, and velocity.

The gas velocity $v_{g}$ in equation (10) is made up of three components. The first component is caused by the motion of the moving rotor relative to the stationary housing (i.e., the combustion chamber is rotating). The second component is squishing velocity caused by the chamber's geometry change. The third component is the velocity induced by the expanding combustion gases. The magnitude and direction of this gas velocity is not known; currently, only laser diagnostic techniques can provide this information. Since this information was not available for this study, the gas velocity is assumed to be equal to the average (time average at the same crank angle, and is not a spatial average) surface tangential velocity of the rotor. This velocity can then be calculated by the following equations: 


$$
\begin{gathered}
V_{g}(\alpha)=\frac{1}{3} \omega D(\alpha) \\
D(\alpha)=9 e^{2}+\left(R^{\prime}\right)^{2}+6 e R^{\prime} \cos \frac{2}{3}\left(\frac{\pi}{2}+\alpha\right)
\end{gathered}
$$

The physical properties used in equation (11) are found for each of the eight measurement points along the rotor housing. The locally measured gas pressure and housing temperature are used to generate gas temperature $\left(\mathrm{T}_{\mathrm{g}}\right)$ and average gas side wall temperature $\left(T_{w g}\right)$ by equations $(6)$ and ( 8 ), respectively. The local gas composition can be balanced by equation (4), and the local film temperature calculated from equation (15). The characteristic diameter (D) can be found from equation (11) yielding enough information to calculate velocity $\left(v_{g}\right)$ from equation (10). Thus, at each point all the properties can be estimated and the gas heat transfer coefficient $\left(h_{g}\right)$ from the left hand side of equation (14) can be calculated from equation $(9)$.

The constant terms of the above two correlated equations were derived from a multiple linear regression technique.

The multiple regression determines mathematically how variable $y$ depends on independent variables $x_{1}, x_{2}, x_{3}$, etc. Using matrix mathematics, the relationship between the variables is assumed to be linear, and of the form:

$$
y=a_{0}+a_{1} x_{1}+a_{2} x_{2}+a_{3} x_{3}
$$

The numerical value of the $A_{n}$ are constants. This method provides a least-squares best fit by determining the a's for which the sum of the errors ( $1 . e$. , the difference between the actual and predicted $y^{\prime} s$ ) is zero and the sum of the squared errors is minimum. A coefficient of determination is used to indicate how well the entire equation fits, a value of \pm 1.0 infers a perfect fit. A Lotus 1-2-3 computer program was used to perform this routine.

Based on the experimental data, a stepwise multiple linear regression program was used. This program sought the most significant parameter from a list of candidates provided, and extracted its effect before seeking the next most important parameter. The coefficients were not forced, nor was the order of parameter selection.

\section{Correlation I}

The Nusselt number is described as a function of the Reynolds number, Prandtl Number, and characteristic temperature ratio. This relationship can be represented by an equation of the form,

$$
\begin{gathered}
N_{u}=K \operatorname{Re}^{A} \operatorname{Pr} B\left(\frac{T_{g}}{T_{f, g}}\right)^{C} \\
\frac{n_{g} D}{k}=K\left(\frac{\rho V_{g} D}{\mu}\right)^{A}\left(\frac{C_{p} \mu}{k}\right)^{B}\left(\frac{T_{g}}{T_{f, g}}\right)^{C}
\end{gathered}
$$


The physical properties involved are evaluated at the gas side film temperature, which is defined as:

$$
T_{f, g}=\frac{T_{g}+T_{w g}}{2}
$$

When our experiment data is closely examined, there is a large temperature and pressure difference in RCE between unburned gas and burned gas. In order to derive a more accurate heat transfer equation, we decided that for each correlation, the burned gas case and unburned gas case should be analyzed separately, and discussed below:

Correlation I-A - The Unburned Gas Case. - The experimental data used in this unburned gas mixture correlation were taken from the engine motoring cases and intake/compression cycle of the engine firing cases. Two regressed equations are:

$$
\begin{gathered}
N_{u}=0.062\left(\frac{T_{b}}{T_{f}}\right)^{-4.657}(P r)^{-4.389}(\operatorname{Re})^{0.745} \\
N_{u}=0.3311\left(\frac{T_{b}}{T_{f}}\right)^{-4.552}(\operatorname{Re})^{0.7387}
\end{gathered}
$$

The average error of equations (16) and (17) is 15.25 and 15.26 percent, respectively (table $I$ ). The coefficient of determination of equations (16) and (17) is 0.973 and 0.975 , respectively (tables II and III). Table I reflects that the Prandt l number changes slightly for the unburned gas case. This information, along with the higher confidence in equation (17) indicates that the Prandtl number is not an important parameter in the unburned gas heat transfer equation.

Correlation I-B - Burned Gas Case. - The experimental data used in this burned gas correlation were taken from the combustion/exhaust cycle of engine firing cases. Again, the Prandtl number is not a dominant parameter in the burned gas analysis. Thus the regressed equation is:

$$
N_{u}=13.865\left(\frac{T_{b}}{T_{f}}\right)^{-3.28}(\operatorname{Re})^{0.3906}
$$

The average error of equation (18) is 22.73 percent (table IV) and the coefficient of determination is 0.788 (table $V$ ). Note in equations (17) and (18) the Prandtl number is not included because its value change is very small based on the experimental data; but, if the Prandtl number does vary widely, then it should be included in the correlate equation.

\section{Correlation II}

The gas heat transfer coefficient as a function of gas temperature, pressure, and velocity. This relationship can be represented by an equation of the form: 


$$
h=K^{\prime}(T)^{A^{\prime}}(P)^{B^{\prime}}(V)^{C^{\prime}}
$$

Again, as mentioned before, the burned gas case and unburned gas case were analyzed separately by the multiple linear repression program.

Correlation II-A - Unburned Gas Case. - Two equations were regressed and compared to study whether the bulk gas temperature $\left(T_{b}\right)$ or gas film temperature $\left(T_{f}\right)$ is a dominant parameter. The equations are:

$$
\begin{aligned}
& h(\alpha)=19.402\left(T_{b}\right)^{-0.538}(P)^{0.3593}(v)^{1.2152} \\
& h(\alpha)=1.0808\left(T_{f}\right)^{-0.092}(P)^{0.1064}(v)^{1.2152}
\end{aligned}
$$

The average errors of equations (20) and (21), are 18.69 and 19.50 percent respectively, and the coefficients of determination are 0.9201 and 0.9008 , respectively. Thus, we concluded equation (20) is better than equation (21) and the result is shown in table VI.

Correlation II-B - Burned Gas Case. - Two equations are regressed to determine if either bulk gas temperature or gas film temperature is an important parameter.

$$
\begin{aligned}
& h(\alpha)=6.2315\left(T_{b}\right)^{-0.45}(P)^{0.0689}(v)^{1.4327} \\
& h(\alpha)=2.34 .14\left(T_{f}\right)^{-0.941}(P)^{0.1378}(v)^{1.2767}
\end{aligned}
$$

The average errors of equations (22) and (23) are 17.83 and 20.69 percent, respectively; the coefficient of determination is 0.8726 and 0.7059 , respectively. Thus we concluded that equation (22) is a better equation to be used in the burned gas region. The result is shown in table VII.

\section{CONCLUSIONS}

1. The investigation of heat transfer mechanisms in the DISC rotary engine led to different regressed equations for convective heat transfer. A separate equation should be used depending on whether gas is unburned or burned.

There are two equations derived for the unburned gas region

$$
\begin{gathered}
N_{u}=0.3311\left(\frac{T_{b}}{T_{f}}\right)^{-4.552}(R e)^{0.7387} \\
h(\alpha)=19.402\left(T_{b}\right)^{-0.538}(P)^{0.3593}(v)^{0.9794}
\end{gathered}
$$

There are two equations derived for the burned gas region: 


$$
\begin{gathered}
N_{u}=13.865\left(\frac{T_{b}}{T_{f}}\right)^{-3.28}(R e)^{0.3906} \\
h(\alpha)=6.2315\left(T_{b}\right)^{-0.45}(P)^{0.0689}(v)^{1.4327}
\end{gathered}
$$

2. For better pressure resolution, a 10-bit or higher $A-D$ convertor is required in order to reduce the experimental error. In this study, the pressure data digitized by the eight-bit A-D converter does not have adequate resolution in the lower pressure range. For example, if the maximum pressure in the chamber is $3.5 \mathrm{MPa}$, then the incremental pressure change is $3.5 \mathrm{MPa} /\left(2^{8 / 2}\right)$ $=0.027 \mathrm{MPa}$. At peak pressure the error is $3.91 / 500=0.8$ percent, but near the intake and exhaust the error is $3.91 / 14.7=26.6$ percent. 
APPENDIX

A Reynolds number exponent defined in equation (13)

$A^{\prime} \quad$ temperature exponent defined in equation (19)

B Prandtl number exponent defined in equation (13)

$B^{\prime} \quad$ pressure exponent defined in equation (19)

b width of the rotor housing, $\mathrm{ft}$ or (m)

C temperature ratio exponent defined in equation (13)

$C^{\prime} \quad$ velocity exponent defined in equation (19)

$\mathrm{Cm} \quad$ mean piston speed in $\mathrm{ft} / \mathrm{sec}$. Or $(\mathrm{m})$

$\mathrm{Cp} \quad$ specific heat of gas at constant pressure, $\mathrm{Btu} /(\mathrm{lb})\left({ }^{\circ} \mathrm{F}\right)(\mathrm{or} \mathrm{cal} /(\mathrm{g})$ $\left({ }^{\circ} \mathrm{K}\right)$ )

D characteristic length in the gas chamber, ft or ( $m$ )

$d \quad$ characteristic width of the piston, ft or (m)

e eccentricity of rotor journal, ft. or $(m)$

h gas heat transfer coefficient, Btu/(sec) $\left(\mathrm{ft}^{2}\right)\left({ }^{\circ} \mathrm{F}\right)$ or $\left(\mathrm{Kcal} /(\mathrm{sec})\left(\mathrm{m}^{2}\right)\right.$ $\left({ }^{\circ} \mathrm{K}\right)$ )

$h_{g}(\alpha) \quad$ average local gas heat-transfer coefficient, Btu/(sec $)\left(f t^{2}\right)\left({ }^{\circ} \mathrm{F}\right)$ or $\left(\mathrm{Kcal} /(\mathrm{sec})\left(\mathrm{m}^{2}\right)\left({ }^{\circ} \mathrm{K}\right)\right)$ as a function of crank angle

K constant in heat transfer equation, defined in equation (13)

$K^{\prime} \quad$ constant in heat transfer equation, defined equation (19)

k thermal conductivity of gas, Btu/(sec) $(\mathrm{ft})\left({ }^{\circ} \mathrm{F}\right)$ or $\left(\mathrm{cal} /(\mathrm{sec})(\mathrm{m})\left({ }^{\circ} \mathrm{K}\right)\right.$

$\mathrm{k}_{1} \quad$ average thermal conductivity between points 3 and 4 ( $F$ ig. 3 ), $\mathrm{Btu} /(\mathrm{sec})(\mathrm{ft})\left({ }^{\circ} \mathrm{F}\right)$ or $\left(\mathrm{Kcal} /(\mathrm{sec})(\mathrm{m})\left({ }^{\circ} \mathrm{K}\right)\right)$

k2 average thermal conductivity between point 3 and gas side surface $\mathrm{Btu} /(\mathrm{sec})(\mathrm{ft})\left({ }^{\circ} \mathrm{F}\right)$ or $\left(\mathrm{Kcal} /(\mathrm{sec})(\mathrm{m})\left({ }^{\circ} \mathrm{K}\right)\right.$

Nu Nusselt number, hD/k

$n_{j} \quad$ number of moles of component $i$, lb-mole/cycle or ( $g$ - mole/cycle)

$\sum n_{j}$ total number of moles of burned gas, lb-mole/cycle or (g-mole/cycle)

P pressure of the working fluid, psia

Pr Prandtl number, Cp $\mu / k$ 


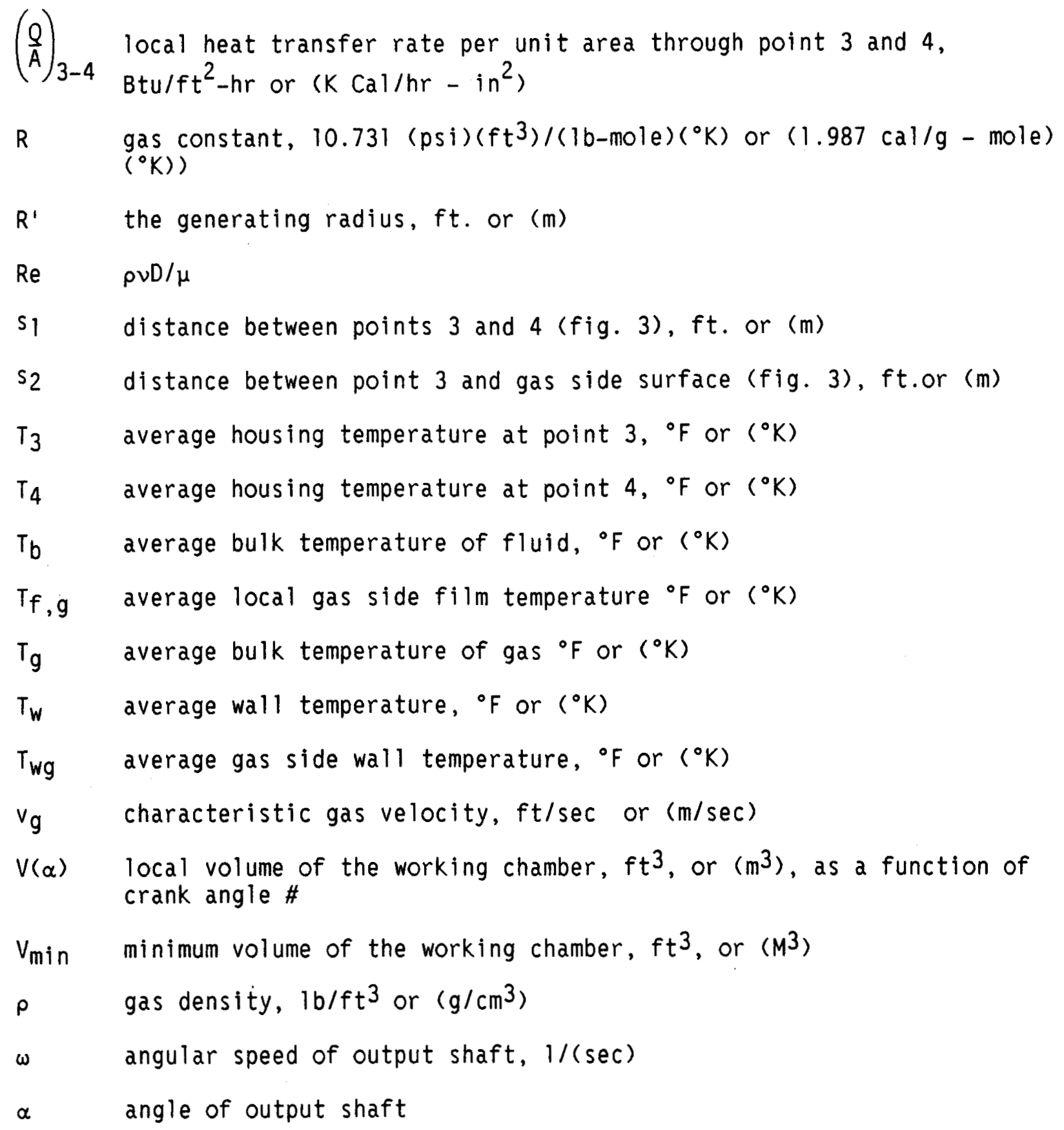




\section{REFERENCES}

1. M.F. Taylor and T.A. Kirchgessner, "Measurements of Heat-Transfer and Friction Coefficients for Helium Flowing in a Tube at Surface Temperatures up to $5900^{\circ}$ R," NASA TN D-133, National Aeronautics and Space Administration, Washington, D.C., 1959.

2. J.R. McCarthy and H. Wolf, "Forced ConvectionHeat Transfer to Gaseous Hydrogen at High Heat Flux and High Pressure in a Smooth, Round, Electrically Heated Tube," ARS Journal, Vol. 30, No. 4, Apr. 1960, pp. 423-425.

3. M. Dalle Donne and F.H. Bowditch, "High Temperature Heat Transfer," Nuclear Engineering, Vol. 8, No. 80, Jan. 1963, pp. 20-29.

4. J.V. Miller and M.F. Taylor, "Improved Methodof Predicting Surface Temperatures in Hydrogen-Cooled Nuclear Rocket Reactor at High Surface to Bulk-Temperature Ratios," NASA TN D-2594, National Aeronautics and Space Administration, Washington, D.C., 1965.

5. G. Woschni, "A Universally Applicable Equation for the Instantaneous Heat Transfer Coefficient in the Internal Combustion Engine," SAE Paper 670931 , Oct. 1967.

6. F. Kreith, "Principles of Heat Transfer," Third Edition, New York, NY: Harper \& Row, 1973.

7. J.A. Roberts, T.J. Norman, J.A. Ekchian, and J.B. Heywood, "Computer Models for Evaluating Premixed and DISC Wankel Engine Performance," SAE Paper 860613, 1986.

8. F.V. Bracco and W.A. Sirignano, "Theoretical Analys is of Wankel Engine Combustion," Combustion Science and Technology, Vol. 7, 1973, pp. 109-123.

9. K.M. Atesmen, "Heat Transfer in Rotary Combustion Engines," Journal of Heat Transfer, Vol. 97, May 1975, pp. 288-294.

10. K. Yamamoto, Rotary Engine, Hiroshima, Japan: Toyo Kogyo Co., Ltd., 1981. 
TABLE I

\begin{tabular}{|c|c|c|c|c|c|c|c|c|c|c|}
\hline \multirow[b]{3}{*}{ Number } & \multicolumn{4}{|c|}{$\begin{aligned} {[\mathrm{Nu}} & =0.0620(\mathrm{~Tb} / \mathrm{Tf})^{\wedge}-4.657 \\
\mathrm{Nu} & =0.3311(\mathrm{~Tb} / \mathrm{Tf})^{\wedge}-4.552\end{aligned}$} & \multicolumn{6}{|c|}{ 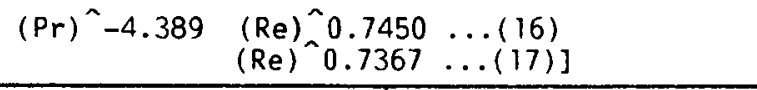 } \\
\hline & \multirow[b]{2}{*}{ Nuf } & \multirow[b]{2}{*}{$\mathrm{Tb} / \mathrm{Tf}$} & \multirow[b]{2}{*}{$\mathrm{Pr}$} & \multirow[b]{2}{*}{$\operatorname{Re}$} & \multicolumn{3}{|c|}{$(16)$} & \multicolumn{3}{|c|}{ (17) } \\
\hline & & & & & Nucal. & $\mathrm{dNu}(\%)$ & abs () & Nucal. & $\mathrm{dNu}(\%)$ & abs() \\
\hline $\begin{array}{l}1 \\
2 \\
3 \\
4 \\
5 \\
6 \\
7 \\
8 \\
9 \\
10 \\
11 \\
12 \\
13 \\
14 \\
15 \\
16 \\
17 \\
18 \\
19 \\
20 \\
21 \\
22 \\
23 \\
24 \\
25 \\
26 \\
27 \\
28 \\
29 \\
30 \\
31 \\
32\end{array}$ & $\begin{array}{c}254.83 \\
136.06 \\
274.14 \\
263.76 \\
100.23 \\
350.6 \\
69.95 \\
198.96 \\
166.53 \\
297.86 \\
87.99 \\
255.28 \\
946.9 \\
71.87 \\
184.1 \\
684.5 \\
179.7 \\
659.6 \\
71.86 \\
188.9 \\
744.5 \\
240.2 \\
716.5 \\
59.23 \\
157.4 \\
862.4 \\
157.1 \\
629.4 \\
237.15 \\
745 \\
71.89 \\
200\end{array}$ & $\begin{array}{l}1.2567 \\
1.1263 \\
1.2833 \\
1.2788 \\
1.1626 \\
1.2734 \\
1.175 \\
1.3057 \\
1.1126 \\
1.2945 \\
1.1684 \\
1.2969 \\
1.172 \\
1.137 \\
1.264 \\
1.242 \\
1.307 \\
1.264 \\
1.186 \\
1.324 \\
1.244 \\
1.296 \\
1.238 \\
1.203 \\
1.335 \\
1.193 \\
1.31 \\
1.242 \\
1.312 \\
1.249 \\
1.205 \\
1.324\end{array}$ & $\begin{array}{l}0.6871 \\
.6903 \\
.6882 \\
.6909 \\
.6891 \\
.6882 \\
.6887 \\
.6873 \\
.6901 \\
.6882 \\
.6889 \\
.6879 \\
.6949 \\
.692 \\
.6905 \\
.6927 \\
.6902 \\
.7188 \\
.7158 \\
.7145 \\
.6925 \\
.6901 \\
.6906 \\
.6887 \\
.688 \\
.6943 \\
.6897 \\
.6923 \\
.6898 \\
.6921 \\
.6898 \\
.6896\end{array}$ & $\begin{array}{rl}24 & 184 \\
4 & 664 \\
27 & 874 \\
31 & 529 \\
6 & 221 \\
36 & 931 \\
3 & 974 \\
23 & 714 \\
6 & 059 \\
36 & 017 \\
5 & 269 \\
31 & 391 \\
121 & 745 \\
5 & 021 \\
30 & 400 \\
126 & 389 \\
31 & 608 \\
135 & 668 \\
5 & 769 \\
33 & 921 \\
166 & 931 \\
41 & 982 \\
124 & 455 \\
5 & 190 \\
30 & 864 \\
115 & 964 \\
28 & 773 \\
161 & 542 \\
41 & 113 \\
143 & 053 \\
5 & 999 \\
35 & 676\end{array}$ & $\begin{array}{r}205.01 \\
98.17 \\
205.26 \\
224.81 \\
105.76 \\
262.43 \\
72.27 \\
168.85 \\
126.46 \\
238.60 \\
91.43 \\
213.93 \\
900.30 \\
98.18 \\
231.56 \\
716.47 \\
204.38 \\
591.70 \\
77.12 \\
174.26 \\
876.03 \\
262.82 \\
728.65 \\
79.01 \\
184.48 \\
802.36 \\
189.14 \\
862.39 \\
244.85 \\
768.34 \\
86.73 \\
211.41\end{array}$ & $\begin{array}{r}-19.55 \\
-27.85 \\
-25.13 \\
-14.77 \\
5.52 \\
-25.15 \\
3.32 \\
-15.13 \\
-24.06 \\
-19.90 \\
3.91 \\
-16.20 \\
-4.92 \\
36.61 \\
25.78 \\
4.67 \\
13.73 \\
-10.29 \\
7.32 \\
-7.75 \\
17.67 \\
9.42 \\
1.70 \\
33.40 \\
17.20 \\
-6.96 \\
20.39 \\
37.02 \\
3.09 \\
3.13 \\
20.65 \\
5.71\end{array}$ & $\begin{array}{r}19.55 \\
27.85 \\
25.13 \\
14.77 \\
5.52 \\
25.15 \\
3.32 \\
15.13 \\
24.06 \\
19.90 \\
3.91 \\
16.20 \\
4.92 \\
36.61 \\
25.78 \\
4.67 \\
13.73 \\
10.29 \\
7.32 \\
7.75 \\
17.67 \\
9.42 \\
1.70 \\
33.40 \\
17.20 \\
6.96 \\
20.39 \\
37.02 \\
3.09 \\
3.13 \\
20.65 \\
5.71\end{array}$ & $\begin{array}{r}198.55 \\
97.24 \\
200.40 \\
222.98 \\
104.06 \\
255.40 \\
71.27 \\
164.42 \\
124.67 \\
232.66 \\
90.01 \\
208.48 \\
897.39 \\
98.34 \\
228.88 \\
708.37 \\
202.27 \\
688.99 \\
89.90 \\
200.90 \\
863.18 \\
259.10 \\
710.73 \\
77.94 \\
180.47 \\
798.55 \\
186.78 \\
848.76 \\
241.27 \\
756.45 \\
86.07 \\
208.51\end{array}$ & $\begin{array}{r}-22.09 \\
-28.53 \\
-26.90 \\
-15.46 \\
3.82 \\
-27.15 \\
1.89 \\
-17.36 \\
-25.14 \\
-21.89 \\
2.30 \\
-18.33 \\
-5.23 \\
36.84 \\
24.32 \\
3.49 \\
12.56 \\
4.46 \\
25.10 \\
6.35 \\
15.94 \\
7.87 \\
-.81 \\
31.59 \\
14.66 \\
-7.40 \\
18.89 \\
34.85 \\
1.59 \\
1.54 \\
19.72 \\
4.25\end{array}$ & $\begin{array}{r}22.09 \\
28.53 \\
26.90 \\
15.46 \\
3.82 \\
27.15 \\
1.89 \\
17.36 \\
25.14 \\
21.89 \\
2.30 \\
18.33 \\
5.23 \\
36.84 \\
24.32 \\
3.49 \\
12.56 \\
4.46 \\
25.10 \\
6.35 \\
15.94 \\
7.87 \\
.81 \\
31.59 \\
14.66 \\
7.40 \\
18.89 \\
34.85 \\
1.59 \\
1.54 \\
19.72 \\
4.25\end{array}$ \\
\hline & & & & & ave. & & 15.25 & & & 15.26 \\
\hline
\end{tabular}


TABLE II

[Number of datasets $=32, Y=-2.78006$ $-4.65772 \times 1-4.38901 \times 2+0.745065$ $x 3$, Coefficiency of determination $=$ $0.974892]$

\begin{tabular}{|c|c|c|c|}
\hline$Y$ & $X 1$ & $X 2$ & $X 3$ \\
\hline 5.540596 & 0.228489 & -0.37527 & 10.09344 \\
4.913095 & .118937 & -.37062 & 8.447628 \\
5.613638 & .249434 & -.37367 & 10.23544 \\
5.575039 & .245922 & -.36976 & 10.35866 \\
4.607467 & .150658 & -.37236 & 8.735685 \\
5.859645 & .241690 & -.37367 & 10.51680 \\
4.247780 & .161268 & -.37294 & 8.287528 \\
5.293103 & .266739 & -.37498 & 10.07382 \\
5.115175 & .106699 & -.37091 & 8.709300 \\
5.696623 & .258124 & -.37367 & 10.49174 \\
4.477223 & .155635 & -.37265 & 8.569595 \\
5.542360 & .259976 & -.37411 & 10.35427 \\
6.853193 & .158711 & -.36398 & 11.70968 \\
4.274858 & .128393 & -.36816 & 8.521384 \\
5.215479 & .234281 & -.37033 & 10.32219 \\
6.528688 & .216722 & -.36715 & 11.74711 \\
5.191288 & .267734 & -.37077 & 10.36116 \\
6.491633 & .234281 & -.33017 & 11.81796 \\
4.274719 & .170586 & -.33435 & 8.660254 \\
5.241217 & .280657 & -.33617 & 10.43178 \\
6.612712 & .218331 & -.36744 & 12.02533 \\
5.481471 & .259282 & -.37091 & 10.64499 \\
6.574378 & .213497 & -.37019 & 11.73169 \\
4.081428 & .184818 & -.37294 & 8.554488 \\
5.058790 & .288931 & -.37396 & 10.33734 \\
6.759719 & .176471 & -.36485 & 11.66103 \\
5.056882 & .270027 & -.37149 & 10.26719 \\
6.444766 & .216722 & -.36773 & 11.99252 \\
\hline
\end{tabular}

TABLE III

[Number of datasets $=32, Y=-1.10530$ $-4.55257 \times 1+0.736769 \times 2$, Coefficiency of determination = $0.973064]$

\begin{tabular}{|r|r|c|}
\hline 5.540596 & 0.228489 & 10.09344 \\
4.913095 & .118937 & 8.447628 \\
5.613638 & .249434 & 10.23544 \\
5.575039 & .245922 & 10.35866 \\
4.607467 & .150658 & 8.735685 \\
5.859645 & .241690 & 10.51680 \\
4.247780 & .161268 & 8.287528 \\
5.293103 & .266739 & 10.07382 \\
5.115175 & .106699 & 8.709300 \\
5.696623 & .258124 & 10.49174 \\
4.477223 & .155635 & 8.569595 \\
5.542360 & .259976 & 10.35427 \\
6.853193 & .158711 & 11.70968 \\
4.274858 & .128393 & 8.521384 \\
5.215479 & .234281 & 10.32219 \\
6.528688 & .216722 & 11.74711 \\
5.191288 & .267734 & 10.36116 \\
6.491633 & .234281 & 11.81796 \\
4.274719 & .170586 & 8.660254 \\
5.241217 & .280657 & 10.43178 \\
6.612712 & .218331 & 12.02533 \\
5.481471 & .259282 & 10.64499 \\
6.574378 & .213497 & 11.73169 \\
4.081428 & .184818 & 8.554488 \\
5.058790 & .288931 & 10.33734 \\
6.759719 & .176471 & 11.66103 \\
5.056882 & .270027 & 10.26719 \\
6.444766 & .216722 & 11.99252 \\
\hline
\end{tabular}


TABLE IV

$\left[\mathrm{Nu}=13.865(\mathrm{~Tb} / \mathrm{Tf})^{\wedge}-3.280(\operatorname{Re})^{\wedge} 0.3906 \ldots(18)\right]$

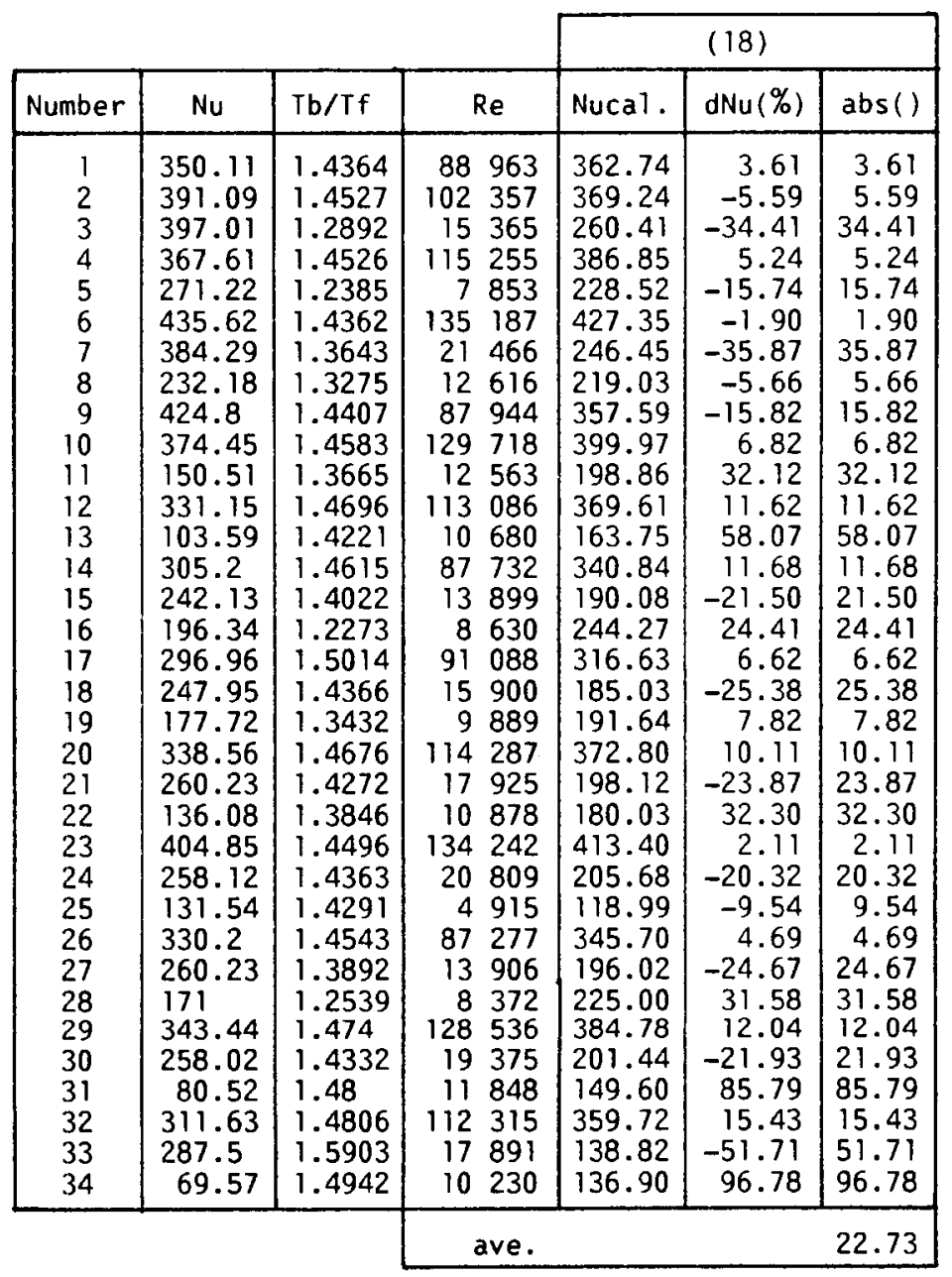

TABLE V

N Number of datasets $=34$, $Y=2.629-3.280 \quad \times 1$ $+0.3906 \times 2$, coefficiency of determination $=0.788]$

\begin{tabular}{|c|c|c|}
\hline$Y$ & $X 1$ & $X 2$ \\
\hline 5.858247 & 0.362139 & 11.39597 \\
5.968937 & .373423 & 11.53622 \\
5.983961 & .254021 & 9.639847 \\
5.907022 & .373355 & 11.65490 \\
5.602930 & .213900 & 8.968650 \\
6.076770 & .362000 & 11.81441 \\
5.951397 & .310641 & 9.974225 \\
5.447512 & .283297 & 9.442721 \\
6.051618 & .365129 & 11.38445 \\
5.925458 & .377271 & 11.77311 \\
5.014029 & .312252 & 9.438511 \\
5.802571 & .384990 & 11.63590 \\
4.640440 & .352134 & 9.276128 \\
5.720967 & .379463 & 11.38204 \\
5.489474 & .338042 & 9.539572 \\
5.279847 & .204816 & 9.062999 \\
5.693597 & .406398 & 11.41958 \\
5.513227 & .362279 & 9.674074 \\
5.180209 & .295054 & 9.199178 \\
5.824701 & .383628 & 11.64646 \\
5.561565 & .355714 & 9.793951 \\
4.913242 & .325411 & 9.294497 \\
6.003516 & .371287 & 11.80739 \\
5.553424 & .362070 & 9.943140 \\
4.879310 & .357044 & 8.500047 \\
5.799698 & .374524 & 11.37684 \\
5.561565 & .328728 & 9.540075 \\
5.141663 & .226258 & 9.032648 \\
5.839012 & .387979 & 11.76396 \\
5.553037 & .359909 & 9.871738 \\
4.388505 & .392042 & 9.379914 \\
5.741816 & .392447 & 11.62906 \\
5.661222 & .463922 & 9.792053 \\
4.242333 & .401590 & 9.233079 \\
\hline & & \\
\hline
\end{tabular}


TABLE VI

$\left[h=19.402 \quad(\mathrm{~Tb})^{\wedge}-0.538 \quad(P)^{\wedge} 0.3593 \quad(v)^{\wedge} 0.9794 \ldots(20)\right]$

\begin{tabular}{|c|c|c|c|c|c|c|c|}
\hline \multirow[b]{2}{*}{ Number } & \multirow[b]{2}{*}{$h$} & \multirow[b]{2}{*}{$T b$} & \multirow[b]{2}{*}{$P$} & \multirow[b]{2}{*}{ 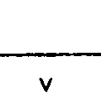 } & \multicolumn{3}{|c|}{ (20) } \\
\hline & & & & & hcal. & $\operatorname{dh}(\%)$ & $\operatorname{abs}()$ \\
\hline $\begin{array}{r}1 \\
2 \\
3 \\
4 \\
5 \\
6 \\
7 \\
8 \\
9 \\
10 \\
11 \\
12 \\
13 \\
14 \\
15 \\
16 \\
17 \\
18 \\
19 \\
20 \\
21 \\
22 \\
23 \\
24 \\
25 \\
26 \\
27 \\
28 \\
29 \\
30 \\
31 \\
32\end{array}$ & $\begin{array}{c}116.1 \\
20.52 \\
39.22 \\
92.59 \\
41 \\
91.91 \\
21.69 \\
44.3 \\
102.87 \\
55.03 \\
96.7 \\
18.4 \\
37.23 \\
108.5 \\
35.27 \\
87.2 \\
21.56 \\
55.8 \\
102.8 \\
22.51 \\
47.11 \\
59 \\
66.63 \\
64.29 \\
32.65 \\
86.01 \\
22.49 \\
48.71 \\
51.99 \\
74.92 \\
28.69 \\
63.38\end{array}$ & $\begin{array}{c}867.1 \\
785.4 \\
1036 \\
1035.1 \\
1166.2 \\
1144.8 \\
1070 \\
1293.6 \\
1062.9 \\
1160.9 \\
1027.1 \\
917.8 \\
1243.9 \\
911 \\
1144.8 \\
1065.3 \\
917.4 \\
1213 \\
1066.2 \\
929.4 \\
1228.4 \\
1140.8 \\
1237.6 \\
1237.6 \\
940.2 \\
1242.6 \\
934.9 \\
1271 \\
855 \\
1303.3 \\
945.7 \\
1383.7\end{array}$ & $\begin{array}{c}85.99 \\
19.07 \\
65.23 \\
96.93 \\
69.33 \\
101.19 \\
20.07 \\
71.46 \\
105.41 \\
73.09 \\
94.89 \\
20.76 \\
72.96 \\
86.46 \\
68.97 \\
104.6 \\
22.06 \\
75.63 \\
101.21 \\
21.6 \\
74.03 \\
61.07 \\
67.65 \\
70.22 \\
21.3 \\
72.99 \\
19.2 \\
67.68 \\
18.95 \\
74.9 \\
20.75 \\
73.09\end{array}$ & $\begin{array}{l}37.56 \\
15.21 \\
23.53 \\
42.5 \\
26.62 \\
47.4 \\
19.2 \\
29.69 \\
53.96 \\
33.8 \\
42.47 \\
17.2 \\
26.6 \\
37.56 \\
23.53 \\
52.93 \\
21.84 \\
33.78 \\
48.03 \\
19.45 \\
30.08 \\
23.76 \\
27.43 \\
30.06 \\
22.22 \\
34.37 \\
15.31 \\
23.68 \\
22.26 \\
34.43 \\
19.35 \\
29.92\end{array}$ & $\begin{array}{r}87.78 \\
22.23 \\
45.68 \\
94.02 \\
49.43 \\
100.64 \\
24.08 \\
52.59 \\
120.69 \\
63.81 \\
93.63 \\
23.77 \\
48.59 \\
85.64 \\
44.16 \\
117.96 \\
30.71 \\
63.06 \\
105.94 \\
27.02 \\
55.47 \\
42.76 \\
48.87 \\
54.18 \\
30.43 \\
62.50 \\
20.42 \\
41.72 \\
30.77 \\
61.59 \\
26.25 \\
51.52\end{array}$ & $\begin{array}{r}-24.40 \\
8.33 \\
16.47 \\
1.54 \\
20.57 \\
9.50 \\
11.03 \\
18.72 \\
17.32 \\
15.96 \\
-3.18 \\
29.19 \\
30.52 \\
-21.07 \\
25.21 \\
35.27 \\
42.42 \\
13.00 \\
3.06 \\
20.01 \\
17.75 \\
-27.53 \\
-26.65 \\
-15.73 \\
-6.79 \\
-27.33 \\
-9.21 \\
-14.35 \\
-40.82 \\
-17.79 \\
-8.51 \\
-18.71\end{array}$ & $\begin{array}{r}24.40 \\
8.33 \\
16.47 \\
1.54 \\
20.57 \\
9.50 \\
11.03 \\
18.72 \\
17.32 \\
15.96 \\
3.18 \\
29.19 \\
30.52 \\
21.07 \\
25.21 \\
35.27 \\
42.42 \\
13.00 \\
3.06 \\
20.01 \\
17.75 \\
27.53 \\
26.65 \\
15.73 \\
6.79 \\
27.33 \\
9.21 \\
14.35 \\
40.82 \\
17.79 \\
8.51 \\
18.71\end{array}$ \\
\hline & & & & & & & 18.69 \\
\hline
\end{tabular}


TABLE VII

$\left[h=6.2315 \quad(T b)^{\wedge}-0.450 \quad(P)^{\wedge} 0.0689 \quad(v)^{\wedge} 1.4327 \ldots(22)\right]$

\begin{tabular}{|c|c|r|r|r|r|r|r|}
\hline Number & $h$ & Tb & P & $v$ & hcal & dh(\%) & abs() \\
\hline 1 & 58.57 & 1973.6 & 170.93 & 39.74 & 57.03 & -2.62 & 2.62 \\
2 & 50.59 & 1681.6 & 31.53 & 31.72 & 39.50 & -21.93 & 21.93 \\
3 & 38.55 & 1019 & 16.72 & 24.98 & 33.64 & -12.73 & 12.73 \\
4 & 20.18 & 882.6 & 17.25 & 15.68 & 18.46 & -8.54 & 8.54 \\
5 & 63.61 & 2294.1 & 188.8 & 43.79 & 61.67 & -3.05 & 3.05 \\
6 & 56.53 & 1912.2 & 37.17 & 36.62 & 46.32 & -18.07 & 18.07 \\
7 & 40.63 & 1341.1 & 22.81 & 28.84 & 37.31 & -8.16 & 8.16 \\
8 & 17.6 & 971.7 & 19.69 & 18.1 & 21.91 & 24.48 & 24.48 \\
9 & 68.59 & 2095.4 & 193.76 & 47.99 & 73.38 & 6.98 & 6.98 \\
10 & 58.62 & 1875 & 37.54 & 40.14 & 53.33 & -9.02 & 9.02 \\
11 & 33 & 1483.7 & 25.99 & 31.61 & 41.03 & 24.33 & 24.33 \\
12 & 20.25 & 1056.8 & 22.05 & 19.84 & 24.25 & 19.75 & 19.75 \\
13 & 81.42 & 2050.9 & 196.21 & 54.86 & 89.82 & 10.32 & 10.32 \\
14 & 59.84 & 1956.3 & 40.52 & 45.88 & 63.70 & 6.45 & 6.45 \\
15 & 34.23 & 1669.8 & 30.26 & 36.13 & 47.61 & 39.09 & 39.09 \\
16 & 62.98 & 1945.5 & 168.34 & 37.8 & 53.38 & -15.25 & 15.25 \\
17 & 53.43 & 1629.1 & 30.52 & 31.61 & 39.78 & -25.56 & 25.56 \\
18 & 34.92 & 1080.4 & 17.71 & 24.89 & 32.73 & -6.28 & 6.28 \\
19 & 71.34 & 2179.8 & 202.86 & 54.96 & 87.82 & 23.10 & 23.10 \\
20 & 59.15 & 1929.1 & 38.87 & 45.96 & 64.08 & 8.33 & 8.33 \\
21 & 64.27 & 2168.2 & 199.61 & 47.77 & 71.93 & 11.92 & 11.92 \\
22 & 26.15 & 1601 & 27.92 & 31.46 & 39.57 & 51.33 & 51.33 \\
23 & 64.81 & 1853.5 & 160.53 & 37.94 & 54.66 & -15.66 & 15.66 \\
24 & 77.3 & 2022.6 & 181.6 & 43.79 & 65.09 & -15.79 & 15.79 \\
25 & 82.98 & 1541.8 & 29.97 & 36.62 & 50.28 & -39.41 & 39.41 \\
26 & 72.84 & 2017.5 & 186.56 & 47.99 & 74.44 & 2.20 & 2.20 \\
27 & 86.25 & 1515.5 & 30.34 & 40.14 & 57.84 & -32.94 & 32.94 \\
28 & 85.94 & 1984 & 189.81 & 54.86 & 90.96 & 5.85 & 5.85 \\
29 & 80.86 & 1647.3 & 34.12 & 45.88 & 68.01 & -15.89 & 15.89 \\
30 & 52.84 & 1316.6 & 23.86 & 36.13 & 52.12 & -1.35 & 1.35 \\
31 & 66.53 & 1880.8 & 162.74 & 37.8 & 54.07 & -18.73 & 18.73 \\
32 & 76 & 2093.8 & 194.86 & 54.96 & 89.18 & 17.34 & 17.34 \\
33 & 35.65 & 1420.9 & 25.05 & 36.2 & 50.68 & 42.15 & 42.15 \\
34 & 67.17 & 2107.4 & 194.01 & 47.77 & 72.71 & 8.25 & 8.25 \\
35 & 26.15 & 1601 & 27.92 & 31.46 & 39.57 & 51.33 & 51.33 \\
\hline & & & & & $a v e$ & & 17.83 \\
\hline
\end{tabular}




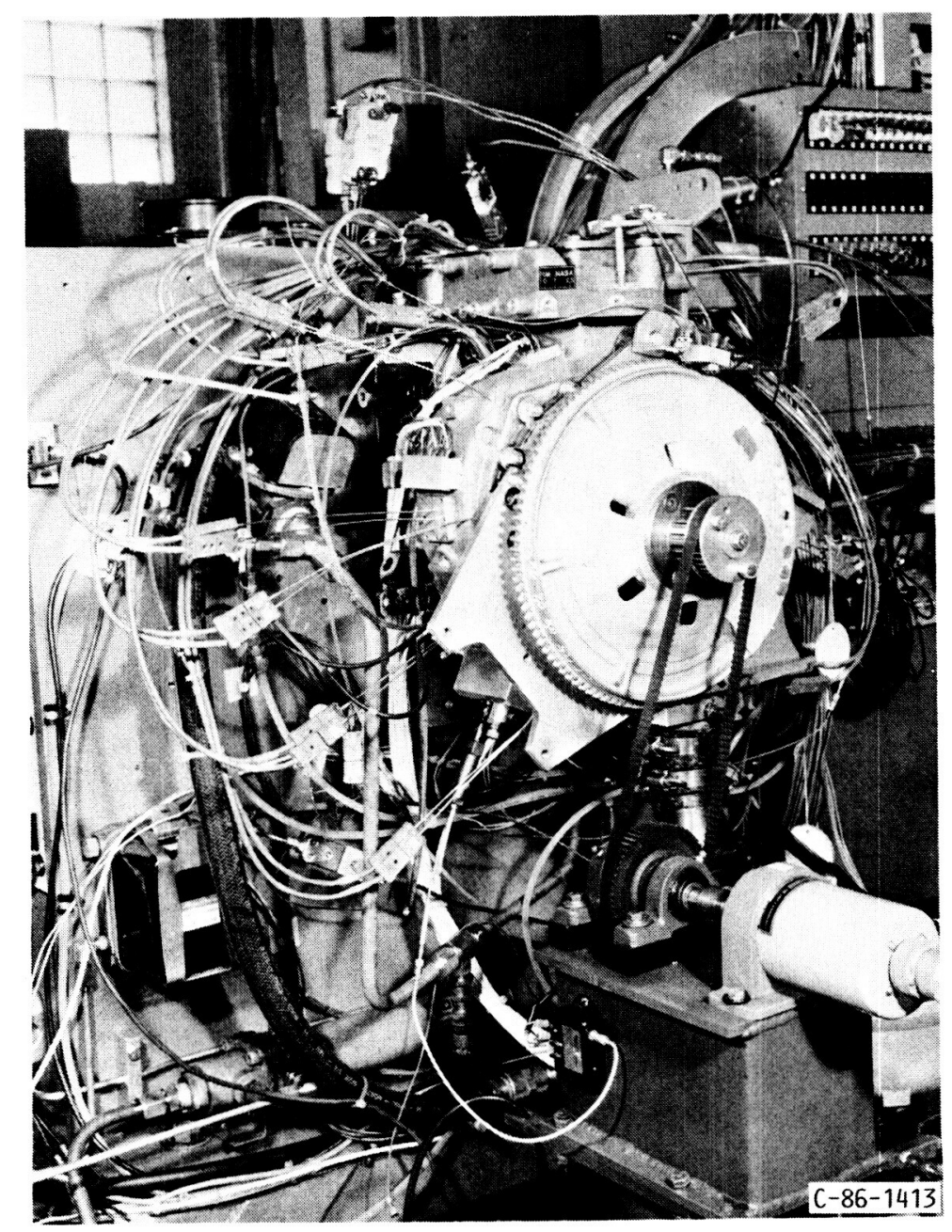

FIGURE 1. - INSTRUMENTED OMC ENGINE.

ORIGINAL PAGE IS

OE POOR QUALITY

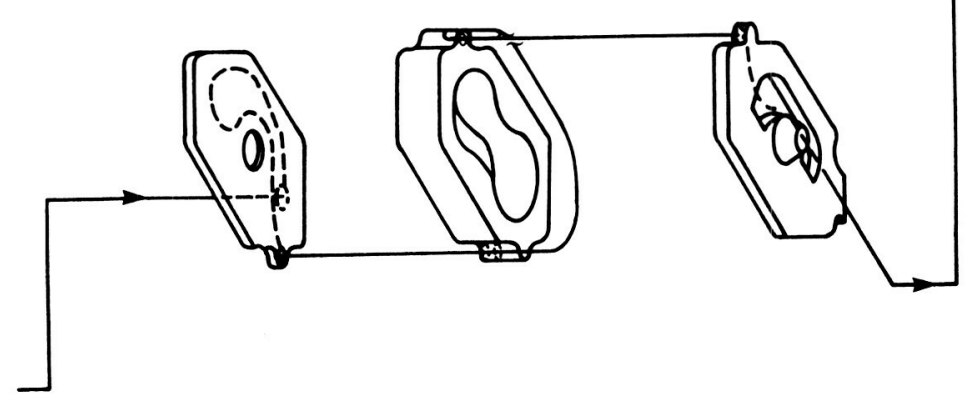

FIGURE 2. - COOLANT FLOW THROUGH ENGINE. 


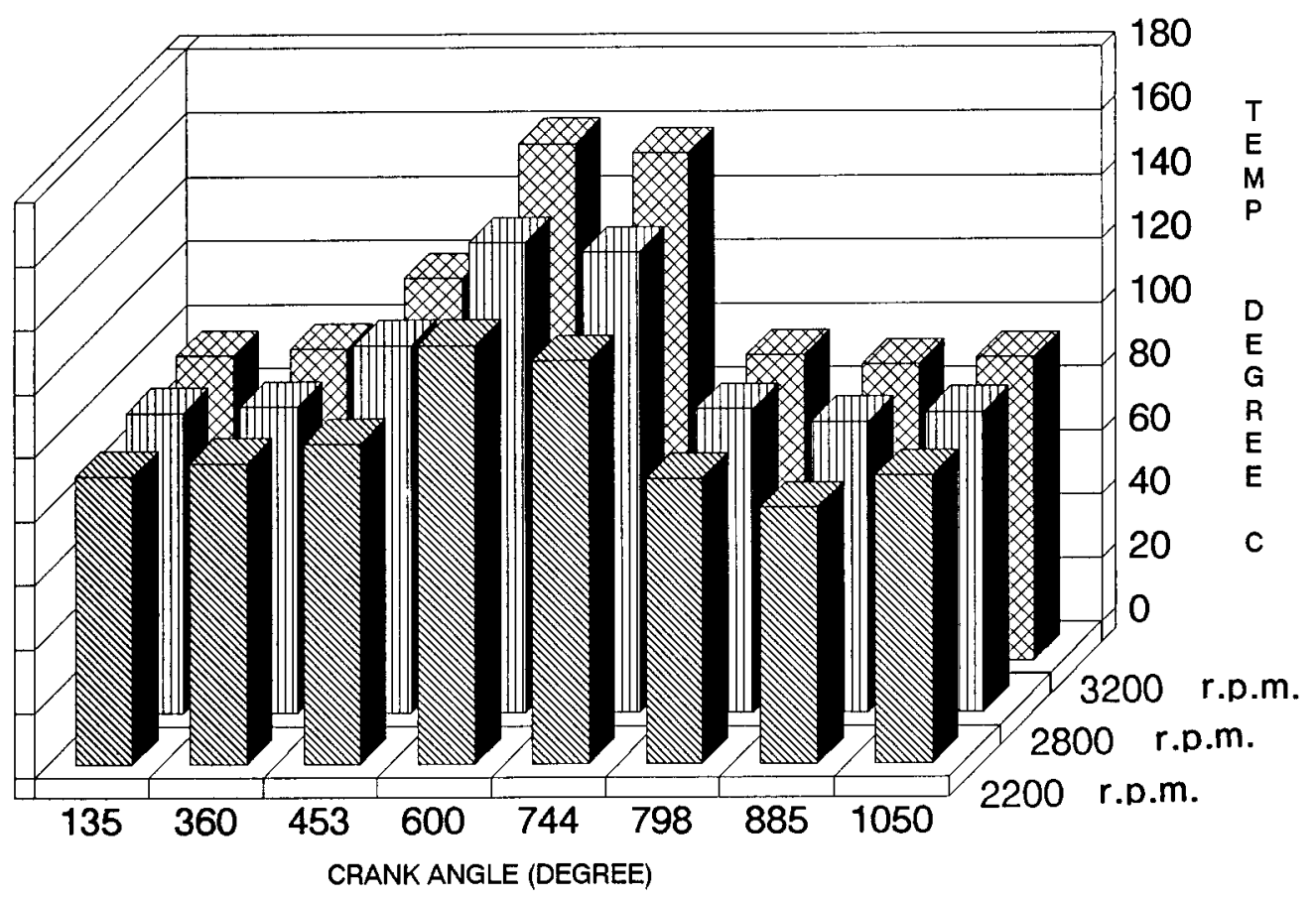

FIGURE 3. - TIME AVERAGE WALL TEMPERATURE. GAS SIDE WALL TEMPERATURE VERSUS C.A.

ORIGINAL PAGE IS

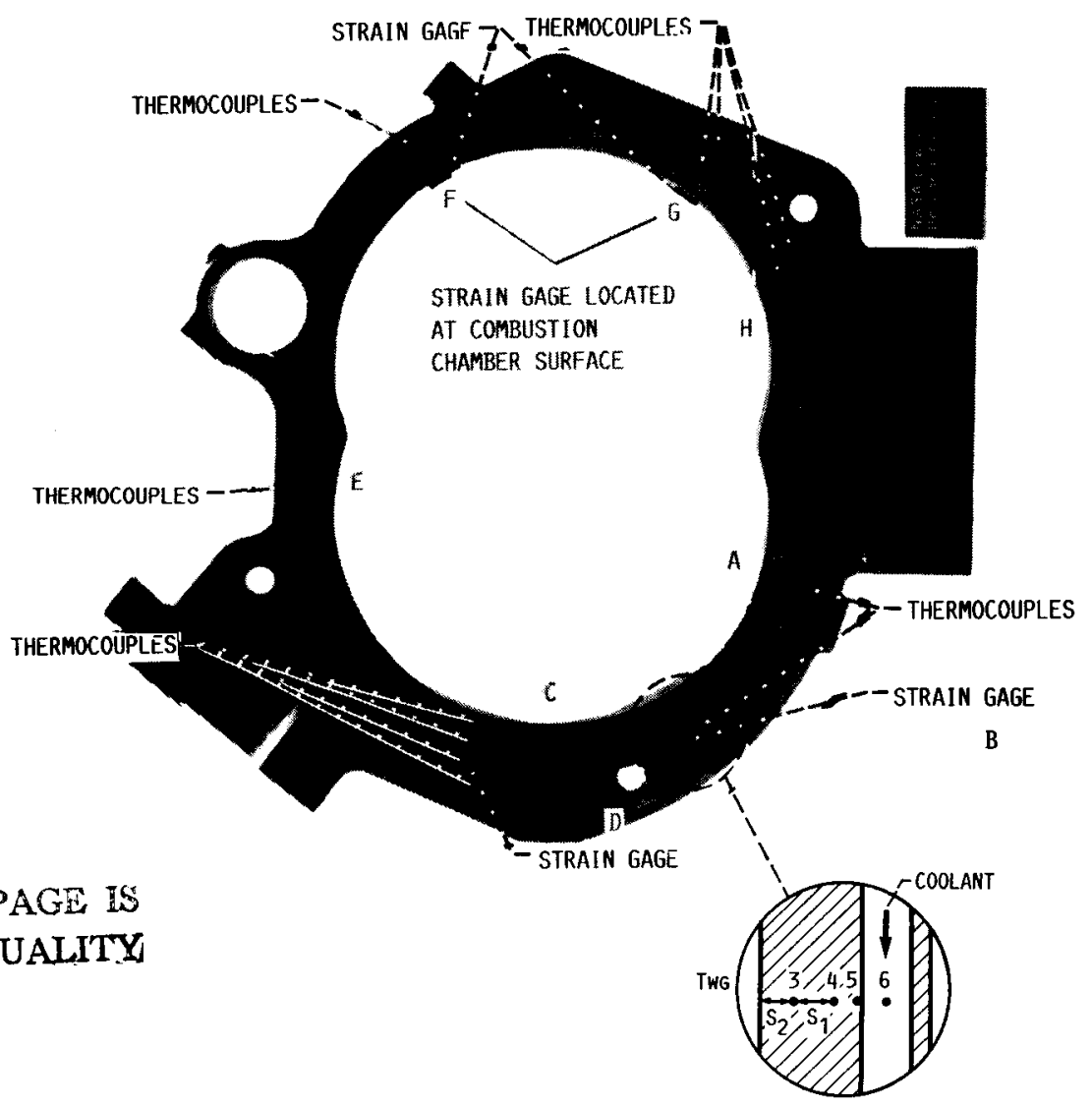

FIGURE 4. - STRAIN GAGES AND THERMOCOUPLES LOCATION. 


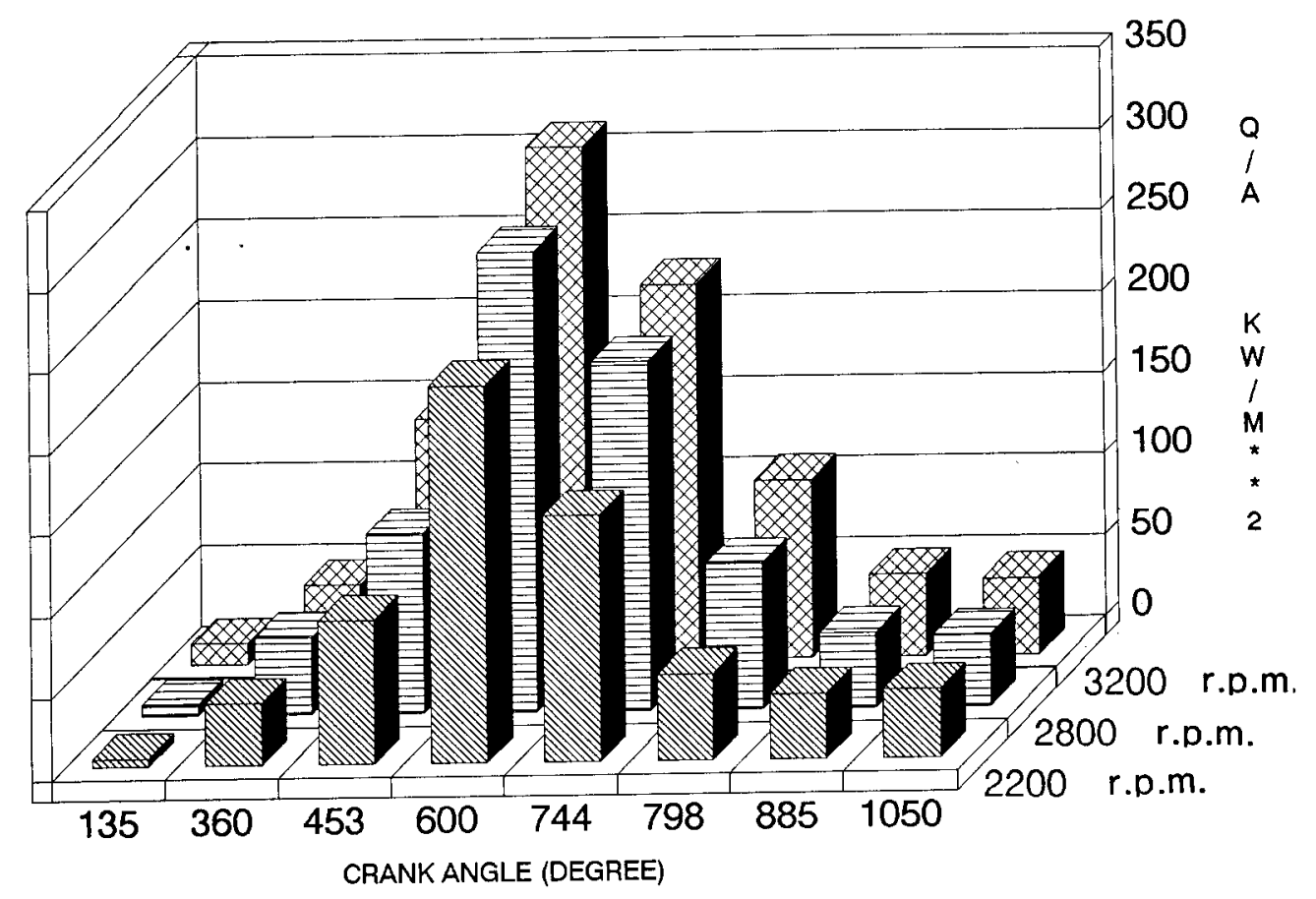

FIgURE 5. - AVERAGE HEAT FLUX PER UNIT AREA. HEAT FLUX PER UNIT AREA VERSUS C.A.

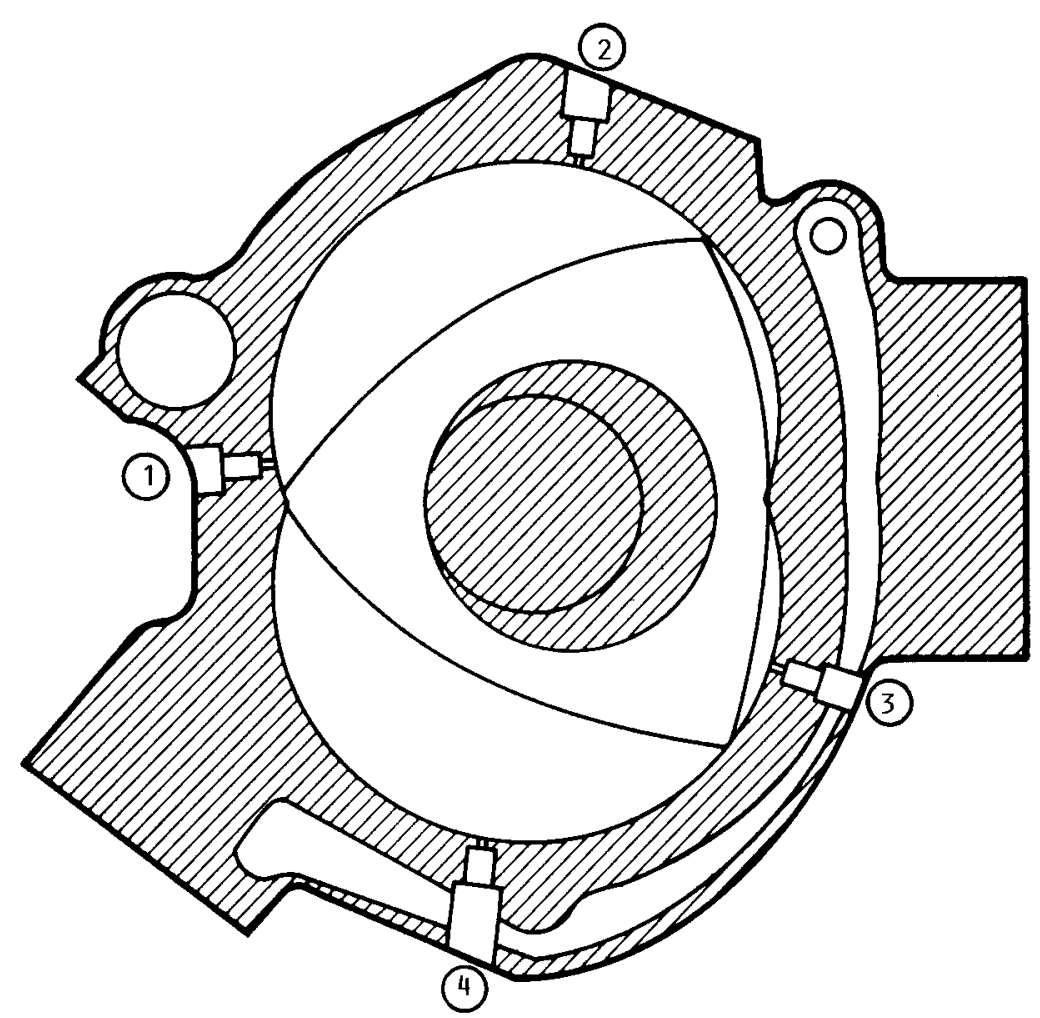

FIGURE 6. - PRESSURE TRANSDUCER LOCATIONS. 


\author{
ORIGINAI PAGE IS \\ OF POOR QUALITY
}

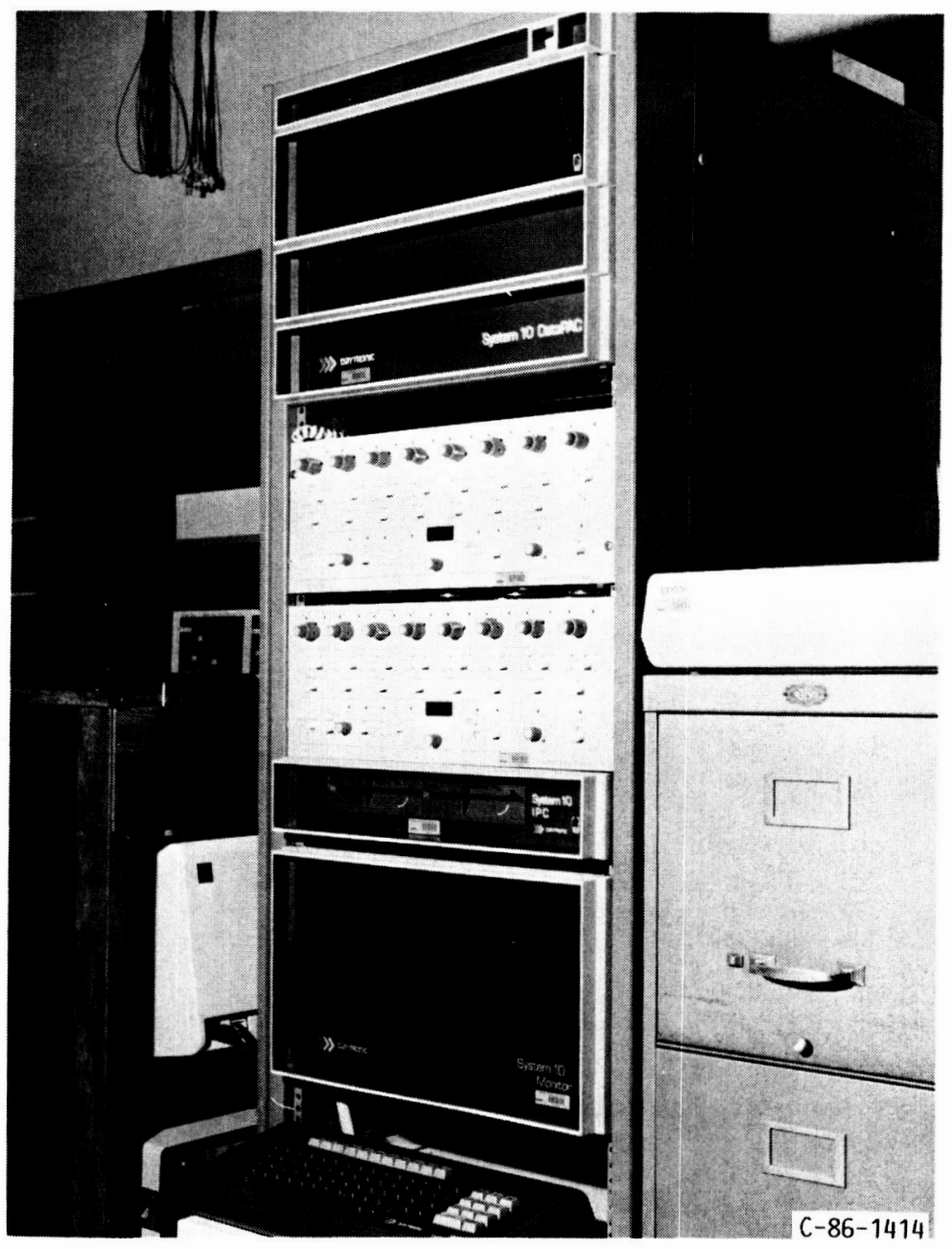

FIGURE 7. - A-D REAL TIME DATA RECORDING SYSTEM. 


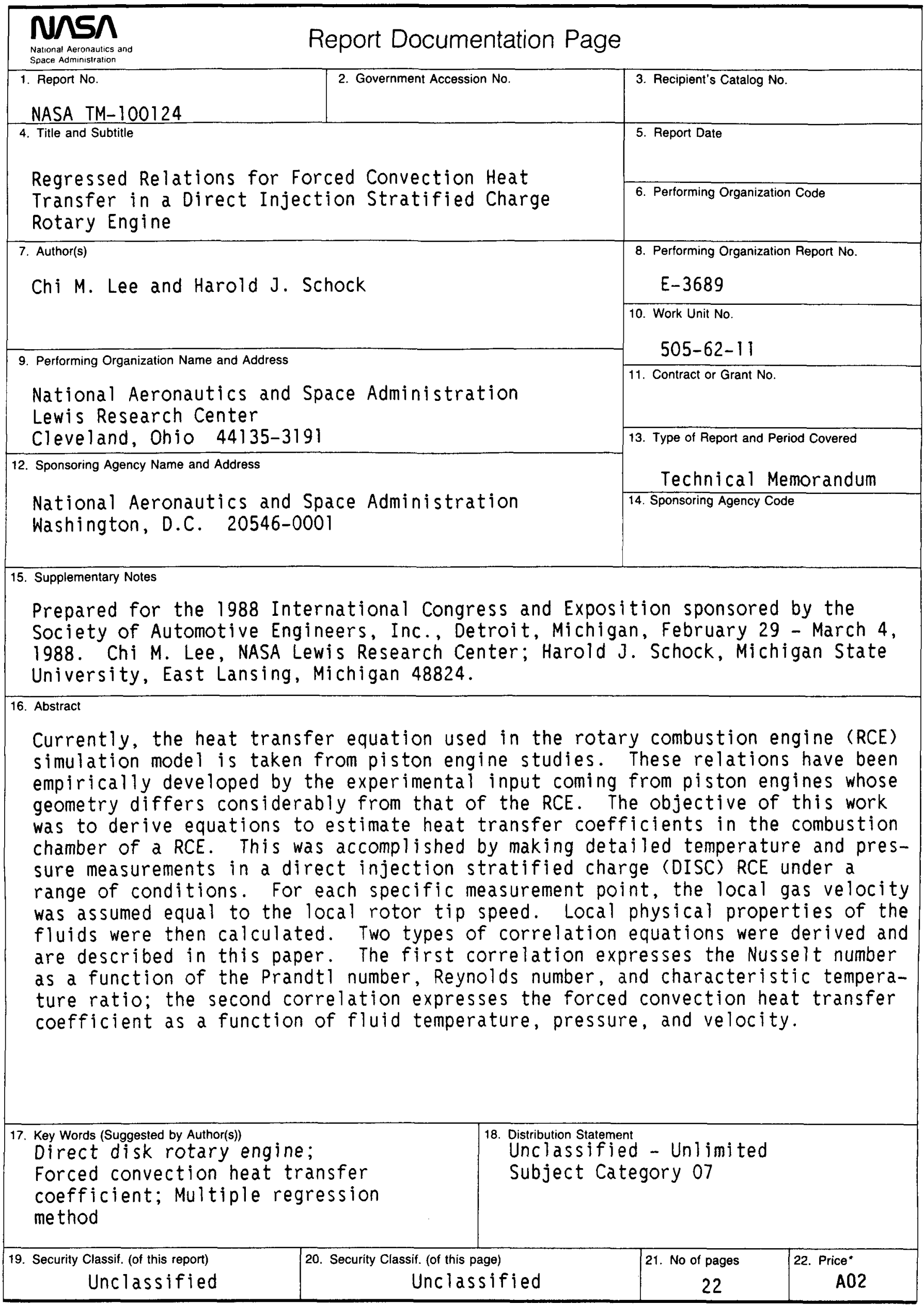

